\title{
A BIOLOGICALLY MEANINGFUL PROBABILITY DESCRIPTION OF PLANKTON STOCKS
}

\author{
by \\ JAMES JAY ANDERSON ${ }^{1}$ ) and SUTOMO ${ }^{2}$ )
}

ABSTRACT

Plankton standing stocks can be described with a gamma probability distribution based on a stochastic logistic equation. The stock is characterized by a carrying capacity and a randomness coefficient.

ABSTRAK

"Standing stock" plankton dapat dijelaskan dalam bentuk sebaran peluang gamma yang didasarkan atas persamaan pertumbuhan stokastik. "Standing stock" ini dicirikan oleh suatu daya dukung (carrying capacity) dan koefisien keacakan.

\section{INTRODUCTION}

A problem in plankton research is how to characterize fluctuating stocks in a statistically rigorous and biologically meaningful manner. Many statistical methods are available to describe plankton distributions, but they generally do not have clear biological meanings. Dynamic models of plankton generally do not represent populations .statistically.

CASSIE (1962) noted that the distribution of many organisms is dispersed so that the probability of observing a large standing stock is less than of observing a small stock. This feature is evident if data, grouped over an interval of time, is displayed in a histogram of stock level vs. frequency. Cassie demonstrated that several probability density functions (pdf) will fit the histogram. Cassie did not offer biological meanings to the pdf.

A number of investigators (Levins 1969, PIELOU 1969, MAY 1973) have shown that one pdf, the gamma distribution, can be interpreted biologically in terms of a stochastic form of the logistic growth equations. In this paper we review this theory and demonstrate that a plankton stock expressed as volume of material captured in a net can be described with the gamma distribution. This analysis allows a stock to be characterized in terms of a carrying capacity and a variability factor.

1) Fisheries Research Institute, University of Washington, Seattle, Washington, ILS.A. -)

2) Ambon Research Station, National Institute of Oceanology, Ambon, Indonesia. 
THEORY

VERHULST (1845) presented a "logistic" equation to describe the rate of change of a population as determined by the difference between a birth, or doubling rate, and a density dependent death rate. The equation can be written

$$
\mathrm{dx} / \mathrm{dt}=\operatorname{rx}(\mathrm{l}-\mathrm{x} / \mathrm{K})
$$

where $\mathrm{x}$ is the population level, $\mathrm{t}$ is time, $\mathrm{r}$ is the intrinsic growth rate, and $\mathrm{K}$ is the population carrying capacity of the environment.

The solution of Eq. (1) is

$$
\mathrm{x}(\mathrm{t})-1 /[(\mathrm{K} / \mathrm{Xo}-\mathrm{l}) \exp (-\mathrm{rt})+1]
$$

where Xo is the initial value of $x$. For all initial conditions $x(t)$ asymptotically approaches $\mathrm{K}$ with time.

The theory assumes that the birth rate, per individual, is independent of the population while the death rate, per individual, increases with the population. It is generally assumed that the death rate increase results from higher resource competition at larger population levels. Although these factors are perhaps the most important in determining the population, the equation does not account for environmental variability, so the simple logistic equation does not provide a good fit to data except in special situations.

Many of the additional factors that control a population fluctuate over time and space, and can be represented by a stochastic form of the logistic equation,

$$
\mathrm{dx} / \mathrm{dt}=\mathbf{r x}(1-\mathrm{x} / \mathrm{K})+\sqrt{\mathbf{2}} \mathrm{i}(\mathrm{t}) \mathrm{fx}
$$

The new term is the stochastic rate that rapidly oscillates, taking on positive and negative values over time. The rate of oscillation is described by $\mathrm{i}(\mathrm{t})$, which randomly fluctuates about zero, with a zero expected value and a variance of one. This term is called a white noise function. The magnitude of the stochastic rate is characterized by $\mathrm{f}$ and

\section{$\sqrt{2}$ simplifies the form of the pdf.}

A numerical solution of the stochastic logistic equation (Appendix A) is presented (Figure 1) for two sets of model parameters (Table 1) that have the same statistical properties as observations from Ambon Bay, Indonesia. The intrinsic rate was set to $r=0.25$ and $i(t)$ assumes a new random value for each integration step, $T=1$. Since the stochastic term is proportional to $\mathrm{x}$ the stochastic rate is larger for higher $\mathrm{x}$. This feature results in $\mathrm{x}$ being more aften below $\mathrm{K}$. 


\section{A BIOLOGICALLY MEANINGFUL PROBABILITY}
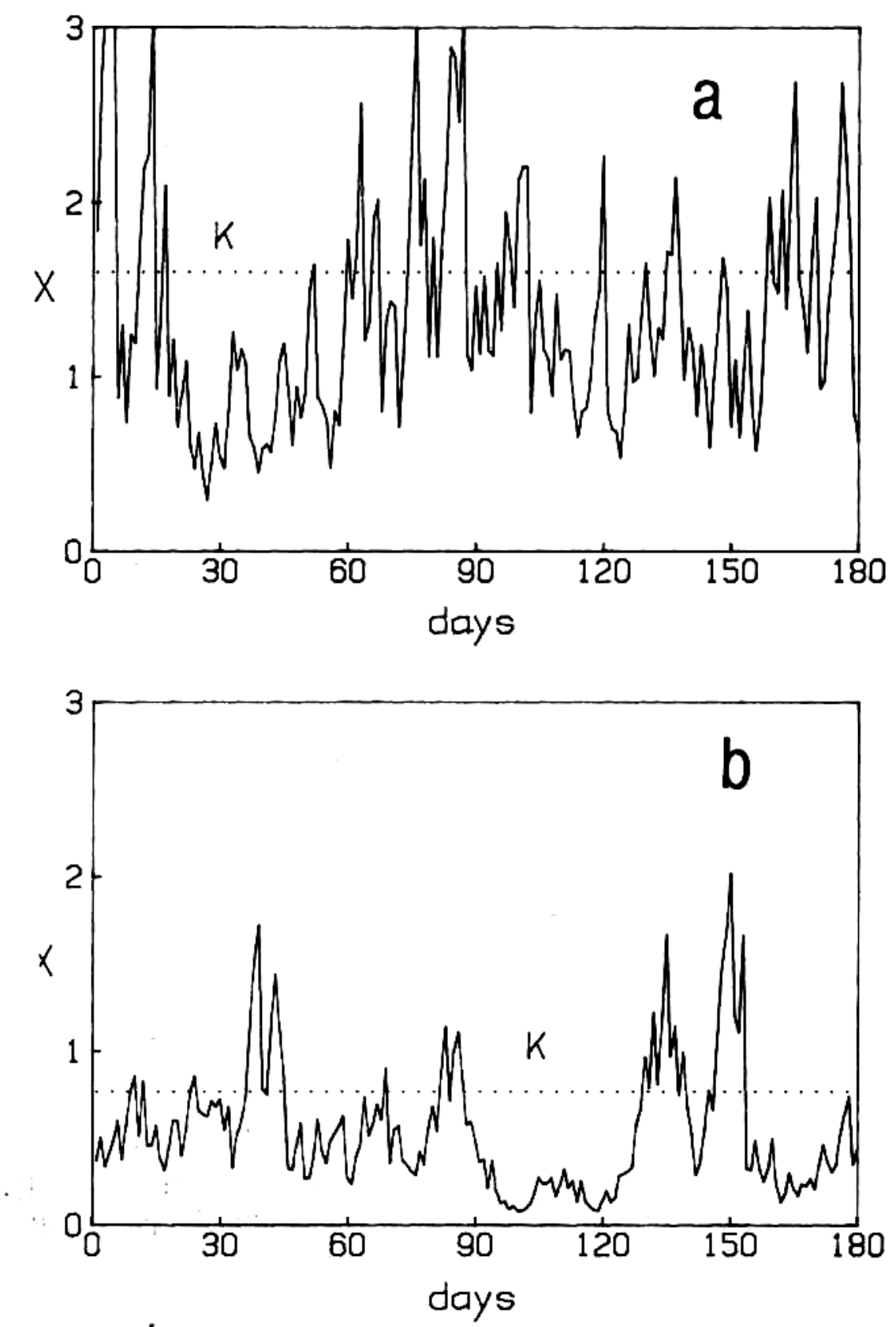

Figure 1. Plankton volume (x) vs time (days) calculated according to Appendix A using model parameters (Table 1) corresponding to inner (Figure la) and outer (Figure lb) parts of Ambon Bay. 
Table L Model parameters for a numerical solution of $\mathrm{x}(\mathrm{t})$ according to Appendix A. Set A corresponds to data from inner Ambon Bay (Fig. la) and Set B to data from outer Ambon Bay Figure lb). Mean and standard deviation are calculated from model results.

\begin{tabular}{lcc}
\hline & $\begin{array}{c}\text { Set A } \\
\text { Inner Bay }\end{array}$ & $\begin{array}{c}\text { Set B } \\
\text { Outer Bay }\end{array}$ \\
\hline Intrinsic rate (r) & 0.25 & 0.25 \\
Random rate (f) & 0.24 & 0.27 \\
Carrying capacity (K) & 1.61 & 0.77 \\
Mean (m) & 1.35 & 0.54 \\
Standard deviation (s) & 0.65 & 0.37
\end{tabular}

To determine the probability distribution of $\mathrm{x}$ a Folker-Planck equation is written to describe the change in the probability of $\mathrm{x}$ with time (GOEL \& RICHTER-DYN 1974).

Using ITO (1944) calculus the Folker-Planck equation is

$\frac{\partial P}{\partial t}=-\frac{\partial}{\partial x}\left\{r x\left(1-\frac{x}{K}\right) P\right\}+f^{2} \frac{\partial^{2}}{\partial x^{2}}\left(x^{2} P\right)$

where $P=P(x, t)$ is the probability of observing $x$ at time $t$.

We are concerned with a system in stochastic equilibrium, where the statistical properties do not change over time. Then $\partial \mathrm{P} / \partial t=0$ and the solution of Eq. (4) is the gamma pdf.

$$
\mathrm{P}(\mathrm{x}, \infty)=\frac{(\mathrm{x} / \mathrm{a})^{\mathrm{b}-1}}{\mathrm{a} \Gamma(\mathrm{b})} \exp .(-\mathrm{x} / \mathrm{a})
$$

where $\Gamma(.)^{1}$ is the gamma function, a is the scale parameter, and b is the shape parameter of the gamma pdf. These parameters are related to the sample mean $\mathrm{m}$, the standard deviation $\mathrm{s}$, and the stochastic logistic equation parameters according to the equations

$$
\begin{aligned}
& \mathrm{a}=\mathrm{Kf}^{2} / \mathrm{r}=\mathrm{s}^{2} / \mathrm{m} \\
& \mathrm{b}=\mathrm{r} / \mathrm{f}^{2}-1=(\mathrm{m} / \mathrm{s})^{2}
\end{aligned}
$$

To illustrate (Figure 2) how the gamma pdf fits the model of $x(t)$, we have plotted histogram of the data in Figure 1 and the pdf using a and $b$ calculated from Eq. (6) using $m$ and $s$ of Table 1.

\footnotetext{
1 The gamma function can be approximated by the Stirling expansion

$\Gamma(\mathrm{b})=\sqrt{ } / 2 \eta \mathrm{e}^{\mathrm{b}-1 / 2} \mathrm{~b}\left[1+\frac{1}{12 \mathrm{~b}}+\frac{1}{288 \mathrm{~b}: 2}-\frac{139}{51840 \mathrm{~b}^{3}}-\frac{571}{2488320 \mathrm{~b}^{4}}\right]$
} 
A BIOLOGICALLY MEANINGFUL PROBABILITY
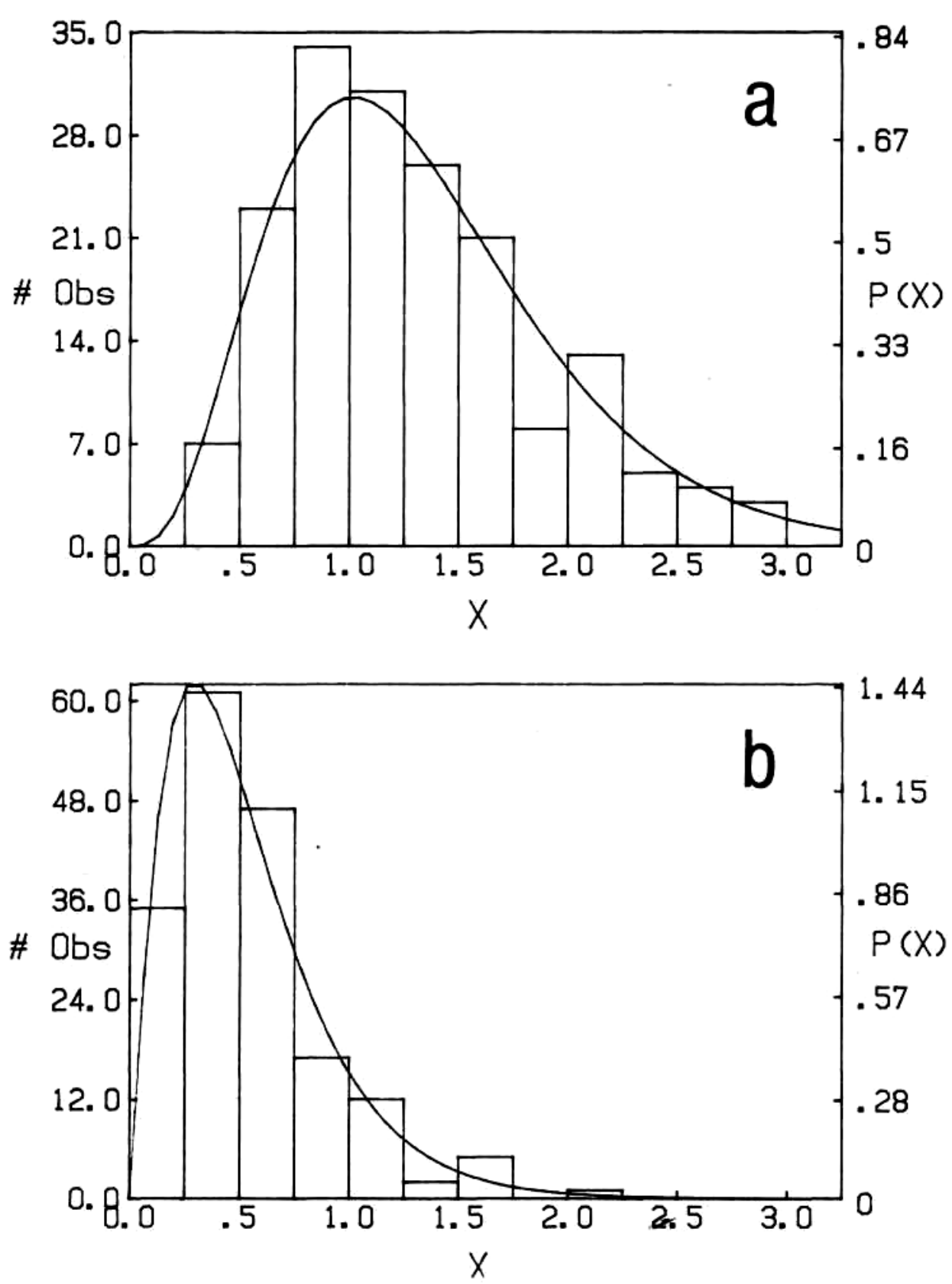

Figure 2. Histogram showing number of observations vs intervals of plankton (x), and the gamma pdf $\mathrm{P}(\mathrm{x})$ vs plankton (x). Figure 2a generated from the data in Figure la, and Figure $2 \mathrm{~b}$ from the data in Figure lb. 
James JAy Anderson \& Sutomo To scale a gamma pdf to

$$
P(x)=F P(x, \infty)
$$

where the scaling factor $\mathrm{F}$ is defined so the area under the pdf is equal to the area of the histogram. Thus

$$
\mathrm{F}=1 / \operatorname{sn}(\mathrm{i}) \mathrm{I}
$$

overlay on a histogram the pdf is written

where $n(i)$ is the number of observations in histogram increment $i$ and $I$ is the width of the increment.

From Eq. (6) the system carrying capacity is

$$
\mathrm{K}=\mathrm{m}+\mathrm{s}^{2} / \mathrm{m}
$$

Equation (9) shows that the carrying capacity is always above the average value of the population by an amount proportional to the variance of the population.

The randomness is characterized by the ratio of the stochastic rate $\mathrm{f}^{2}$ to the deterministic rate $\mathrm{r}$. The randomness coefficient is defined

$$
\mathrm{F}^{2} / \mathrm{r}=1 /\left[(\mathrm{m} / \mathrm{s})^{2}+1\right]
$$

The mode, or most probable value, is

$$
\mathrm{Xm}=\mathrm{K}\left(1-2 \mathrm{f}^{2} / \mathrm{r}\right)=\mathrm{m}=\mathrm{S}^{2} / \mathrm{m}
$$

The mode is always below the population mean value and the carrying

\begin{tabular}{|c|c|c|}
\hline & $\begin{array}{l}\text { Set A } \\
\text { Inner Bay }\end{array}$ & $\begin{array}{c}\text { Set B } \\
\text { Outer Bay }\end{array}$ \\
\hline Carrying capacity (K) & 1.61 & 0.77 \\
\hline Randomness coefficient $\left(\mathrm{f}^{2} / \mathrm{r}\right)$ & 0.19 & 0.32 \\
\hline
\end{tabular}
capacity. Using $\mathrm{m}$ and $\mathrm{x}$ from Table $1, \mathrm{~K}$ and $\mathrm{f}^{2} / \mathrm{r}$ can be computed for the model (Table 2).

Table 2. Stochastic parameters computed from model derived $\mathrm{m}$ and $\mathrm{s}$ according to eq(9) and (10)

\section{PLANKTON IN AMBON BAY}

To demonstrate the use of the gamma pdf we present observations of plankton net volume from Ambon Bay in the Moluccas Islands of eastern Indonesia reported in SuTOMo \& ANDERSON (1984). Plankton 
A BIOLOGICALLY MEANINGFUL PROBABILITY
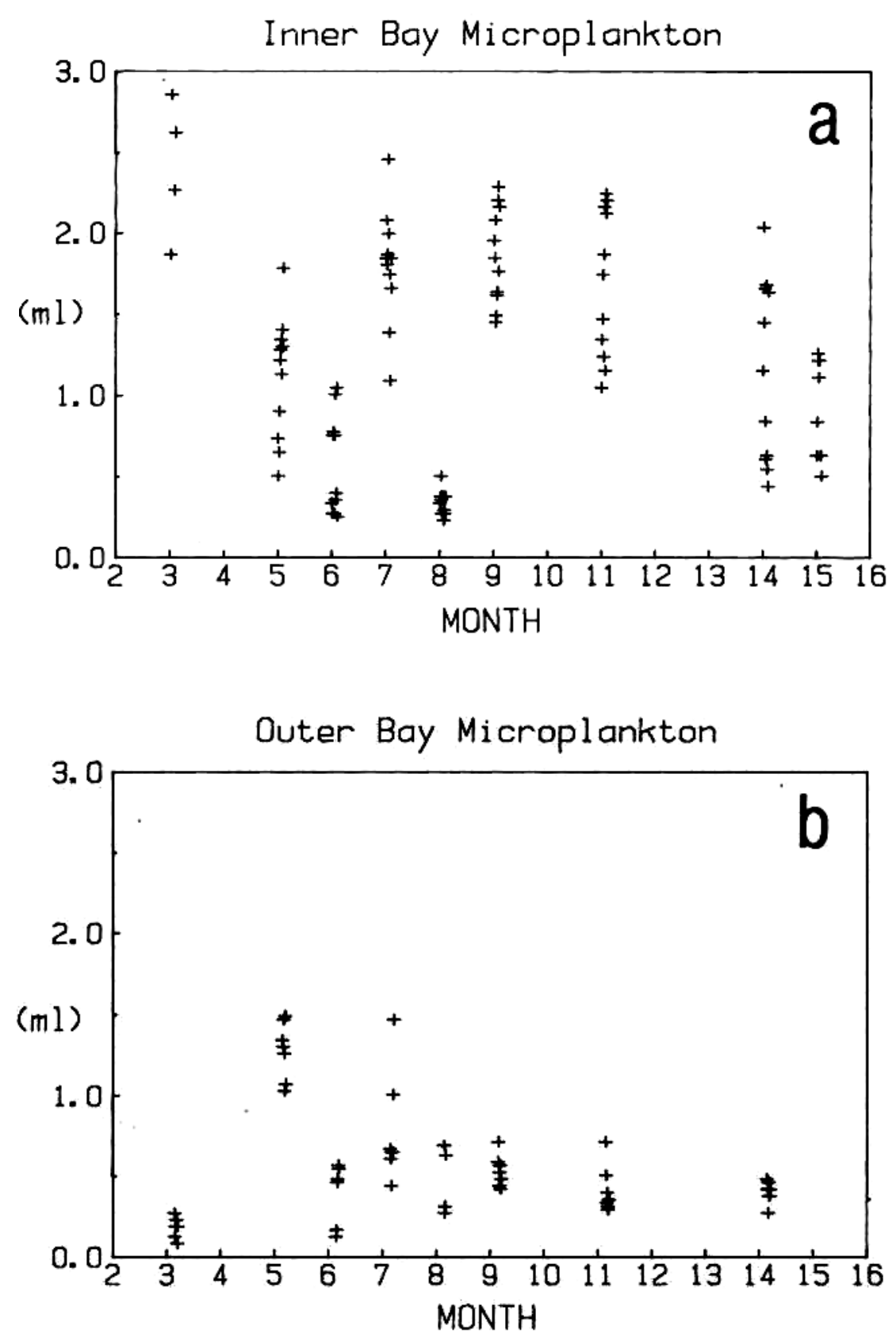

Figure 3. Ambon Bay microplankton volume (ml) for 11 stations in the inner bay (Figure 3b) and 7 stations in the outer bay (Figure 3a) vs month. 
were collected from daylight vertical hauls with a $0.12 \mathrm{~mm}$ mesh net. Eight surveys were made between March 1980 and March 1981 at 11 stations in the shallow inner part of the bay, and 7 stations in the deep outer part of the bay. The net collected clumps of phytoplankton and small zooplankton.

In both parts of the stock fluctuated from month to month (Figure 3 ) in a manner similar to the fluctuation of $x$ in the model (Figure 1). Table 3 gives the observed statistical properties of the Ambon data and the resulting carrying capacities and randomness coefficients calculated from Eq. (9) and (10).

Table 3. Observed and computed properties of plankton distributions in inner and outer parts of Ambon Bay.

Mean (m)

Standard deviation (s)

Carrying capacity (K)

Randomness coefficient (f-/r)
Inner Bay

1,24

0.68

1.61

0.22
Outer Bay

0.54

0.36

0.77

0.29

Histograms with the gamma pdf for Ambon Bay microplankton (Figure 4) are similar to the model distributions (Figure 2) with the mode shifted towards lower values.

The analysis suggests that the carrying capacity in the inner bay is over twice that in the outer bay while the variability factors are about equal. The carrying capacity for integrated chlorophyll in Puget Sound, a temperate estuary on the Pacific Northwest coast of the United States, increases 8 times between winter and summer while the randomness coefficient changes by less than a factor of $1 / 2$, and the average value of about 0.3 (EBBESMEYER, OKUBO, ANDERSON \& CONQUEST, unpublished manuscript). The randomness coefficient is a nondimensional number, so the values in Puget Sound and Ambon Bay can be compared. The fact that the coefficients are similar suggests that the processes producing the variability might be .similar in the two environments. The daily tides, light cycle, and weather may be important in producing the random variations in the net growth rate.

If we assume that the randomness term fluctuates with a period of 1 day, then for the numerical solution (Appendix $A$ ) it follows $T=1$ day, 
A BIOLOGICALLY MEANINGFUL PROBABILITY
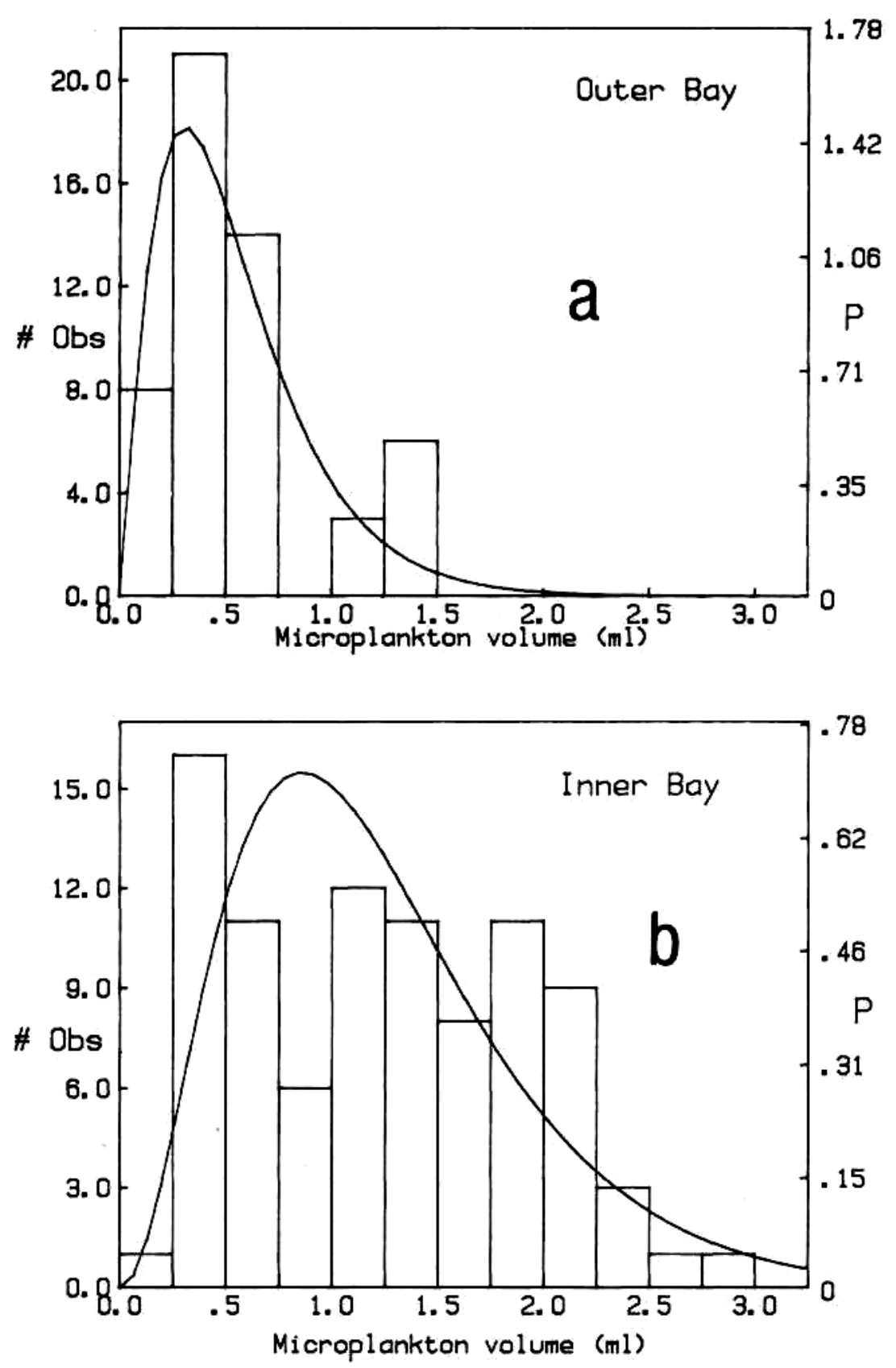

Figure 4. Histogram showing number of observations vs intervals of microplankton volume for inner (Figure 4a) and outer (Figure 4b) Ambon Bay data of Figure 3. 
and so $r=0.25$ day. This implies that the numerical model fits observed data with a plankton doubling every 4 days. Published doubling times for nutrient poor waters range between 0.25 and 0.4/day (PARSONS \& TAKAHASHI 1973). The agreement between the model and data supports our assumption that the variability has a time scale of a day.

The utility of expressing stocks with the gamma pdf ultimately depends on understanding what environmental factors determine $\mathrm{K}$ and $\mathrm{f}^{2} / \mathrm{r}$, and how these factors change from one environment to the next. This initial analysis suggests the carrying capacity changes between inner and outer Ambon Bay, while the randomness coefficient does not. An important task is to investigate what factors control the carrying capacity. As discussed by SUTOMO \& ANDERSON (1984), the predator-prey interactions, sewage, and siltation might be important factors in controlling the plankton carrying capacities of the bay.

\section{ACKNOWLEDGEMENTS}

This work was supported by the US. Agency for International Development Contract No. AID-497-79-100 and by LIPI, the Indonesian Institute of Sciences. We wish to tank Dr Aprilani Soegiarto, Director of the National Institute of Oceanology, and Mr. Atjep Suwartana, Director of the National Institute of Oceanology Ambon Research Station, for their support.

\section{APPENDIX A}

To calculate $\mathrm{x}$ for the stochastic logistic equation the numerical solution of eq(3) is written

$$
x(j+1)=x(j)+[d x / d t] T .
$$

where

$$
d x / d t=r(1-x(j) / K) x(j)+\sqrt{2} i(t(j)) f x(j)
$$

and

$$
T=t(j+1)-t(j)
$$

The white noise term $\mathrm{i}($.$) is produced by a random number generator and$ for the calculations $i$ took on a new random value for each increment $j$. Thus the time scale of the random term and the integration increment are both $\mathrm{T}$. 


\title{
A BIOLOGICALLY MEANINGFUL PROBABILITY
}

\author{
REFERENCES
}

CASsIE, R. M. 1962. Frequency distribution models in ecology of plankton and other orgnisms. J. Anim. Ecol. 31: 65-92.

CoEl, N. S. and N. RICHTER-Dyn 1974. Stochastic Models in Biology. Academic Press, New York. 1-269.

ITO, K. 1944. Stochastic Integral. Proc. Imp. Acad. (Tokyo) 20: 519.

LEVINS, R. 1969. The effects of random variations of diferent types on population growth. Proc. Nat. Acad. Set. 62: 1061-1065.

MAY, R. M. 1973. Stability and complexity in model ecosystems. Monogr. in Population Biol. No. 6, Princeton Univ. Press. 265 pp.

PARSON, T., and M. TAKAHASHI 1973. Biological oceonographic processes. Pergamon Press, Oxford. 186 pp.

PIELOU, E. C. 1969. An introduction to mathematical ecology. Wiley, New York. 532 pp.

Sutomo, and J. J. Anderson 1984. Phytoplankton and zooplankton abundance in Ambon Bay. Mar. Res. Indonesia (in present number).

Verhuist, P. F. 1845. Recherches mathematiques sur la loi d'accroissement de la population. Mem. Acad. Roy. Belg. 18(1) : 1-38. 